\title{
Cataract surgery in the management of the late complications of lepromatous leprosy in South Korea
}

\author{
T. J. FFYTCHE \\ From St Thomas's Hospital, Lambeth Palace Road, London SE1 7EH
}

SUMMARY Clinical examination of 113 patients in South Korea with lepromatous leprosy and severe visual impairment showed that the main cause of visual loss was the combined effect of corneal and lens opacities associated with small nonreacting pupils and iris atrophy. Cataract surgery with broad iridectomy and inferior sphincterotomy offers these patients with chronic lepromatous complications the best chance of preserving vision. Eighty-one cataract operations were performed under local anaesthesia, and in $90 \%$ vision improved; in $60 \%$ this improvement was 2 Snellen's lines or more.

Leprosy has probably existed in the Korean Peninsular since the 10th century AD, having spread there from China in the wake of the many Chinese invasions that have been such a feature of Korean history, and the disease was still endemic a generation ago. ${ }^{2}$ The Korean population is especiaally susceptible to leprosy for 2 main reasons. Firstly, the climatic conditions are suitable, for contrary to popular belief the disease flourishes as much in temperate climates as in tropical ones and has been seen in Iceland, Alaska, Germany, Russia, Japan, China, and the colder parts of the United States. $^{3}$ Secondly, there is still a large peasant population living at subsistence levels in closeknit communities with their inherent overcrowding and poor sanitation - conditions known to encourage the development and spread of the disease.

Chinese and Mongolian races have a higher incidence of the lepromatous type of leprosy ${ }^{45}$ and a temperate climate also encourages this form ${ }^{4} 6$ and it is lepromatous leprosy that is associated with the major ocular complications which lead to blindness. The only previous epidemiological study in Korea by Holmes in $1957^{2}$ reported ocular complications in $10 \%$ of lepromatous cases, but this figure is certainly too low, as many authors recognise a much higher incidence of ocular involvement in lepromatous leprosy: $51 \%$ in West Malaysia, ${ }^{7} 76 \%$ in Vietnam, ${ }^{8}$ and $89 \%$ in Nepal. ${ }^{9}$ Indeed Pinkerton ${ }^{10}$ and later Harley ${ }^{11}$ felt that all patients with lepromatous leprosy eventually developed ocular complications.

A recent report by Les Amis du Père Damien ${ }^{12}$ on

Correspondence to $\mathrm{Mr}$ T. J. ffytche. the global distribution of leprosy patients shows that there are 28255 registered cases in the Republic of South Korea out of a total population of 36 million, a rate of 0.8 per thousand. This figure must be considered as an underestimate as it takes no account of the large proportion of affected individuals who for some reason or other do not seek attention. The present Korean policy for the care of leprosy patients is to avoid institutionalisation and to aim at resettlement, but many patients prefer to remain in communities among similarly affected individuals, where they can be looked after and supervised by Government resources and welfare organisations often sponsored by foreign charities and the Church. An important centre in the southern part of South Korea is the Wilson Leprosy Centre and Rehabilitation Hospital at Yosu, founded in 1909 as a Presbyterian Mission by Dr. R. M. Wilson. The centre is well known for its orthopaedic work in the management of leprosy and poliomyelitis and for its care of leprosy patients. An associated leprosy community has been in existence for many years, and in 1973 it numbered $509,{ }^{13}$ but has since then been reduced to 201 through an active policy of resettlement (A. M. Topple, personal communication). A few miles to the west the Government-sponsored community on the Island of Sorokdo houses some 2500 individuals, and to the East there are several scattered communities centred around the city of Chinju.

\section{Materials and methods}

The Wilson Leprosy Centre was visited in 1978 and 1979 for the purpose of studying and treating the 
ocular complications of leprosy. During these 2 visits patients were also seen at Sorokdo and Chinju and surgery on selected patients from all 3 centres was carried out. The preliminary results from the visit in 1978 have already been published. ${ }^{14}$ Patients were chosen and referred for surgery because of severe visual disability, thought mainly to be caused by cataract, although the majority had other ocular complications involving the anterior segment. These patients therefore represented a highly selected group showing the late complications of lepromatous leprosy, and no statistical conclusions can be drawn on the incidence of ocular complications in the general leprosy population.

Although over 200 patients with advanced lepromatous eye disease were seen during the 2 visits, only 113 had a full ophthalmic assessment with slitlamp examination. Eighty of these 113 cases were males $(71 \%)$, with ages ranging from 42 to 79 (mean 62.7). The age of onset of the disease was difficult to determine accurately in many patients, but the average duration was estimated as 41 years in males (17-63) and 35 years in females (12-54). In 5 cases leprosy had been contracted under the age of 10 ; in 15 patients the disease had been present for more than 50 years and in 2 patients for more than 60 years. Only 4 patients had had leprosy for less than 20 years.

110 patients had the lepromatous form of the disease, 2 had the tuberculoid form, and 1 patient was classed as borderline; only 3 cases had positive skin tests. $85 \%$ of the remaining lepromatous patients had had negative skin tests for at least 5 years, and all patients had received some form of antileprosy therapy, including combinations of chaulmoogra oil, dapsone, lamprene, and steroids, and most patients were still on some form of systemic therapy. Many of the patients had severe involvement of the face and limbs which, coupled with the visual impairment, lead to extreme forms of disability ((Fig. 1).

\section{VISUAL ACUITY}

Visual acuities were measured with glasses, if worn, on a Snellen's test type modified for use with Korean symbols; the relatively few illiterate patients were tested with the standard Snellen E-test. Refractions were not undertaken.

The results of the visual acuity measurements in 224 eyes ( 2 eyes had been enucleated) are shown in Fig. 2. Eighty four of the 113 patients $(74 \%)$ had binocular visual acuity of less than $6 / 60$ and would therefore be eligible for blind registration in the United Kingdom; 13 of these had binocular vision of less than counting fingers and 5 had less than hand movements.

\section{OPHTHALMIC EXAMINATIONS}

An analysis of the ocular findings in the 113 patients examined with the slit-lamp is shown on Table 1. The lid abnormalities included lagophthalmos and trichiasis, and several patients had previously had medial or lateral tarsorrhaphies and other forms of

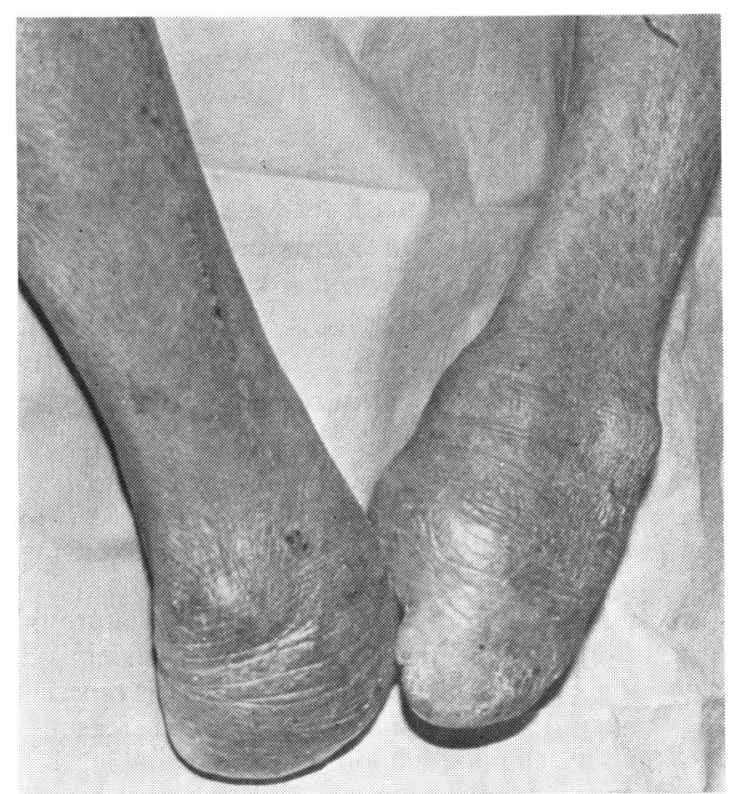

Fig. 1 Deformation of the hands produced by chronic lepromatous leprosy.

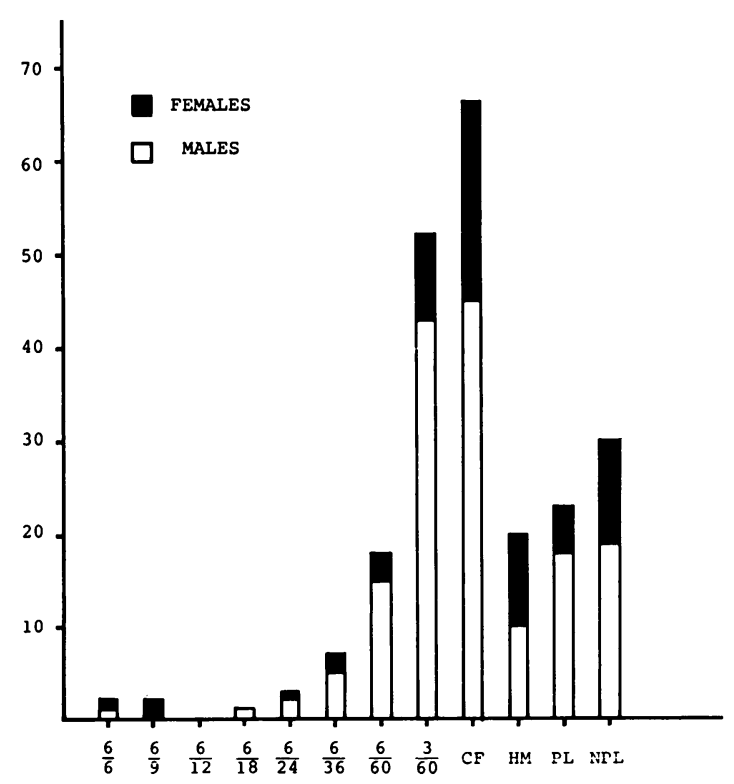

Fig. 2 Visual acuity in 224 leprotic eyes. 
surgery for the complications of facial nerve palsy (Figs. 3 and 4).

Corneal disease was considered to exist if there were significant corneal opacities, though these did not necessarily interfere with sight. A detailed

Table 1 Ocular disease in 113 leprosy patients

\begin{tabular}{llr}
\hline 226 Eyes: & Enucleated & 2 \\
& Phthisis & 17 \\
& Madarosis & 190 \\
& Lid abnormalities & 55 \\
& Dacryocystitis & 2 \\
Corneal disease & 154 \\
& Pterygium & 28 \\
198 Eyes: & Iris atrophy & 113 \\
& Posterior synechiae & 66 \\
& Cataract & 152 \\
& Aphakia & 22 \\
& Dislocated lens & 2 \\
& Glaucoma & 2 \\
\hline
\end{tabular}

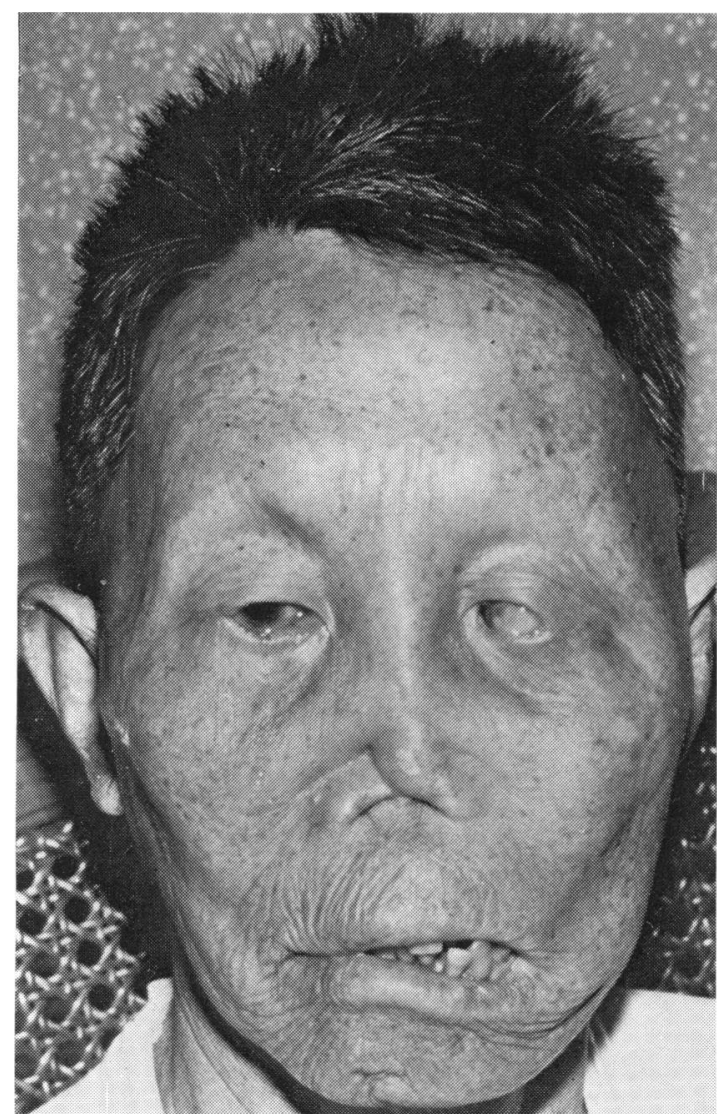

Fig. 3 Patient with advanced lepromatous leprosy showing facial and nasal deformities. Medial and bilateral lateral tarsorrhaphies have been carried out. analysis of the different corneal manifestations was not possible, but it was noted that a form of bandshaped degeneration occurred in 32 nonphthisical eyes $(16 \%)$, and in 14 eyes $(7 \%)$ the cornea was completely vascularised (Fig. 5). In 3 cases there was a lipoid infiltration of the cornea which possibly represented an old corneal leproma (Fig. 6), but in only 3 eyes were enlarged corneal nerves identified. Iris atrophy with loss of stromal architecture and gross thinning was observed in 113 nonphthisical eyes $(57 \%)$, and posterior synechiae occurred in 66 eyes $(33 \%)$, though the 2 conditions were combined in only 49 eyes $(25 \%)$. In 110 eyes $(55 \%)$ the pupil was found to be grossly reduced in size, at times pinpoint, and in 7 eyes there was complete seclusio pupillae. At the time of surgery these small pupils were found to be unreactive to atropine and phenylephrine. Active iritis with aqueous flare and cells was seen only in 3 cases, and a further 6 eyes had old keratic precipitates. Iris pearls were observed in 4

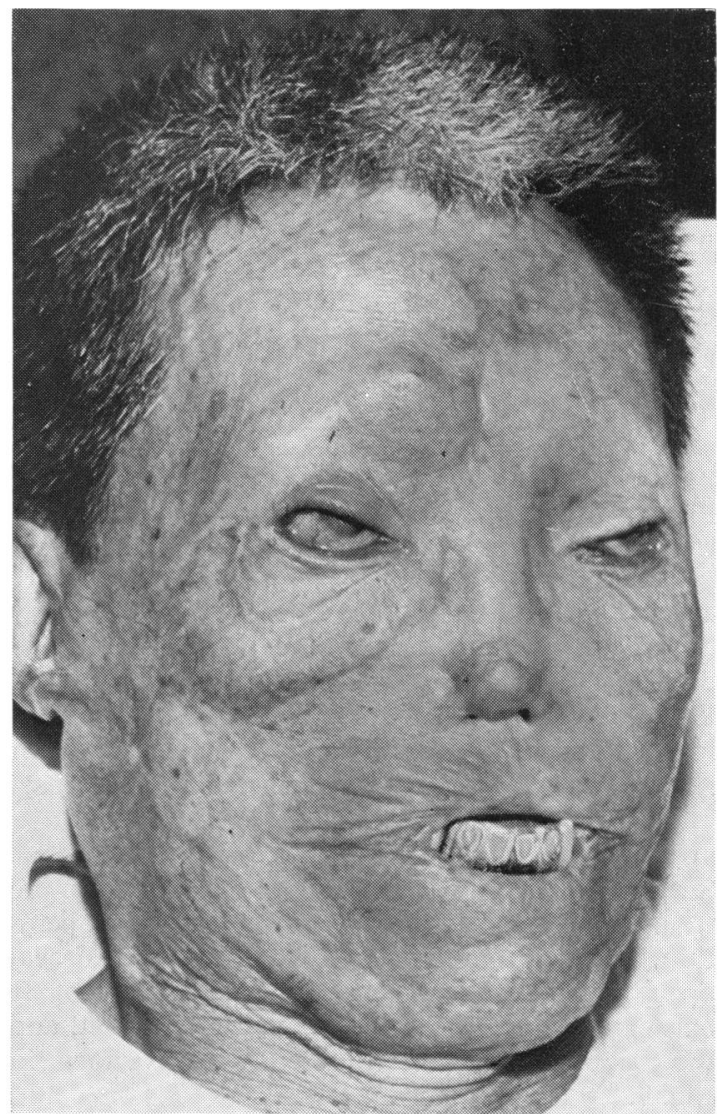

Fig. 4 Patient with lepromatous leprosy showing bilateral facial palsy. An ectropion repair with skin grafts has been carried out on each lower lid. 


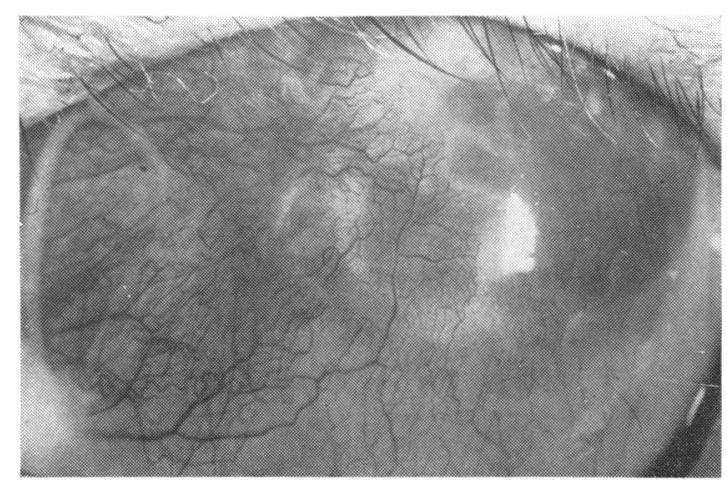

Fig. 5 Vascularised corneal opacity in lepromatous leprosy.

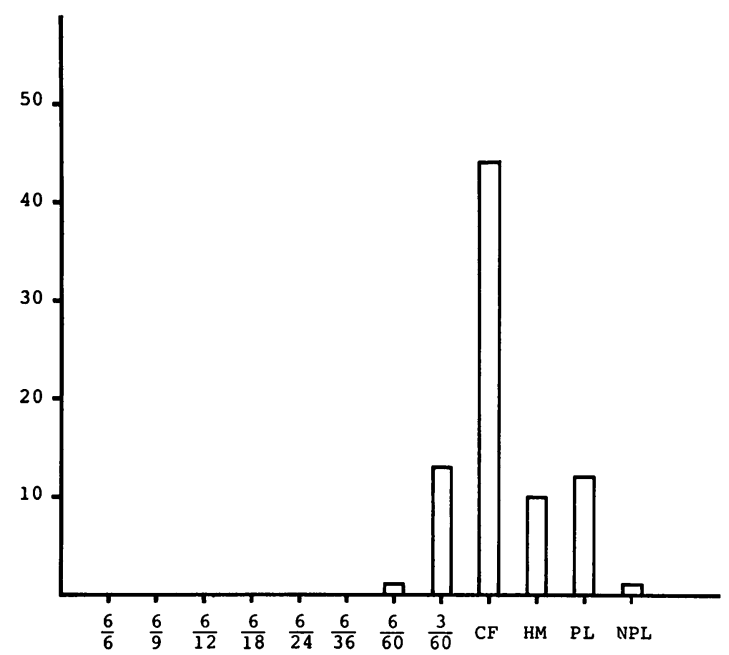

Fig. 7 Preoperative visual acuity in 81 eyes.

cases $(2 \%)$. Examination of the lens was made very difficult by the small nonreacting pupils, but significant lens opacities were observed in 152 eyes $(76 \%)$. Examination of the fundi in 46 patients operated on in 1978 and before failed to show any choroidal or retinal pathology that could be ascribed to leprosy.

\section{SURGERY}

Surgery was offered to those patients who were thought most likely to benefit from cataract operation, and in whom there were no gross axial corneal opacities or evidence of active iritis. A total of 81 lens extractions in 79 patients were carried out, and the preoperative vision in these 81 eyes is shown in Fig. 7.

All cases were operated on under local anaesthesia by an ab-externo technique with a broad iridectomy and inferior sphincterotomy; the lens was removed

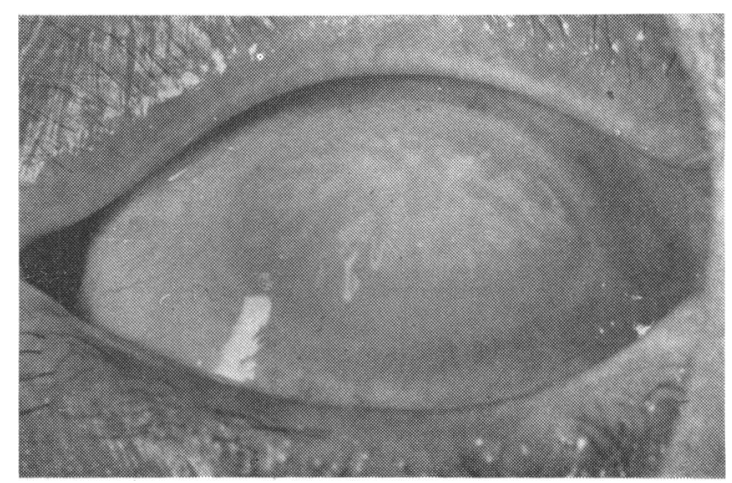

Fig. 6 Irregular lipoid infiltrates in the superficial stromal layers of the cornea in lepromatous leprosy.

by forceps combined with expression in the manner previously described. ${ }^{14}$ Routine antibiotic drops were instilled for 24 hours before surgery and the operation was followed by a subconjunctival injection of steroid and steroid/antibiotic drops. The technique of lens extraction was modified to suit the local conditions and instruments, no cryotherapy being available. An analysis of the surgical procedures and complications is presented in Table 2.

Postoperative visual acuity was measured with a +10 lens after a follow-up period of between 3 and 18 months, and the results are shown on Fig. 8. Comparison of the preoperative and postoperative visual acuity in each of the 81 operations is shown in Fig. 9.

\section{Discussion}

Several factors in the cause of blindness and visual impairment in this group of patients emerge in this small series. In the first place it will be evident that the majority of patients $(97 \%)$ had the lepromatous form of leprosy and in all but 3 cases the disease had been sucessfully treated, as shown by the negative skin tests. Indeed $85 \%$ of the cases had had no evidence of active disease for at least 5 years. The average age of the patients $-61 \cdot 5$ years for men and

Table 2 Eighty-one lens extractions

\begin{tabular}{|c|c|c|}
\hline Intracapsular & 66 & \\
\hline Extracapsular & 15 & $\begin{array}{l}-1 \text { planned } \\
-7 \text { capsule removed }\end{array}$ \\
\hline Vitreous loss & 14 & $\begin{array}{l}-10 \text { intracapsular } \\
-4 \text { extracapsular }\end{array}$ \\
\hline Postop. hyphaema & 3 & \\
\hline Endophthalmitis & 1 & \\
\hline Postop. uveitis & 2 & \\
\hline Retrobulbar haem. & 1 & \\
\hline $\begin{array}{l}\text { Increased corneal } \\
\text { opacification }\end{array}$ & 3 & \\
\hline
\end{tabular}




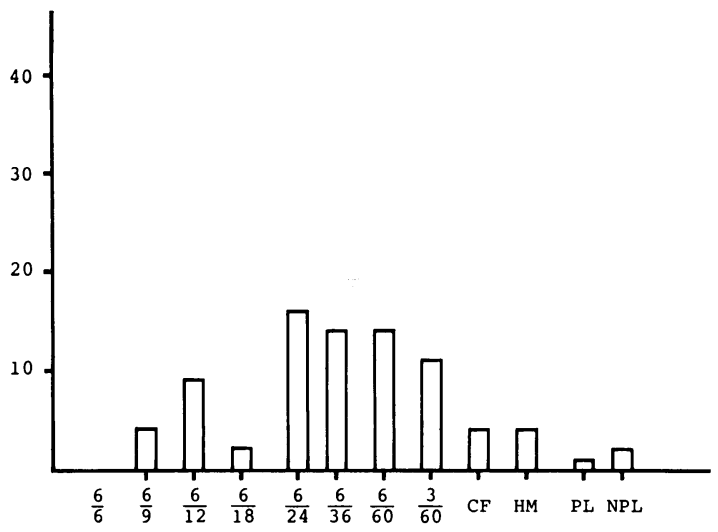

Fig. 8 Postoperative visual acuity in 81 eyes.

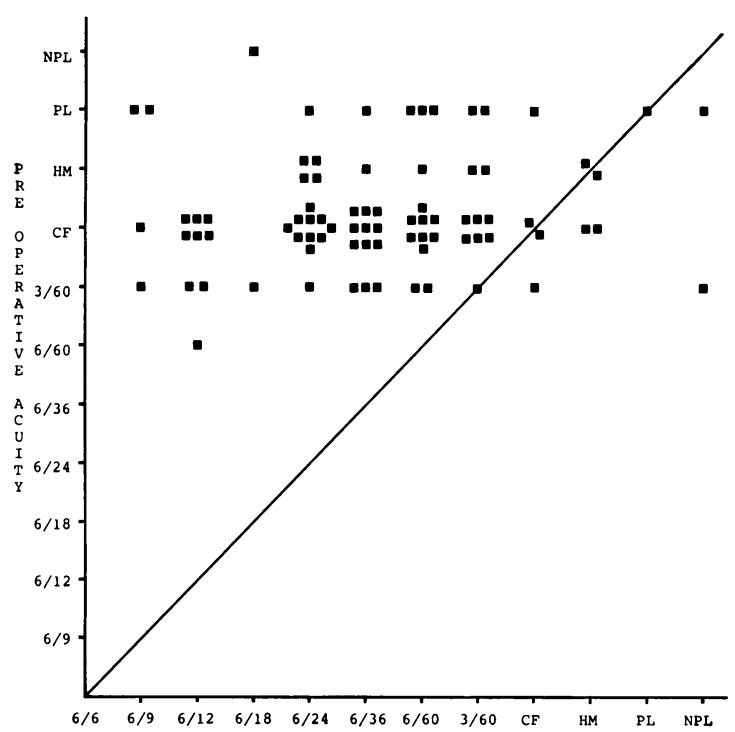

Fig. 9 Postoperative visual acuity in 81 eyes.

62.7 for females-represents a lower average age than that of nonleprosy patients having cataract surgery, and suggests that other factors apart from the ordinary development of senile cataract may be involved in the causation of visual impairment. Clinically it was certainly very difficult in many cases to determine the precise degree of lens opacity present because of the pupil abnormalities and condition of the iris. Almost all the patients had had leprosy for at least 20 years, and the average duration of the disease was 41 years for males and 35 years for females. This high incidence of anterior segment complications in patients with disease of long duration agrees with the findings of other authors who have studied lepromatous leprosy, 410111516 and failure to recognise these late effects may be respons- ible for some of the low figures in the literature on the ocular complications of the disease. The conclusion can be drawn that ocular complications may develop long after the disease has been successfully treated systemically and that no patient with lepromatous leprosy should be regarded as safe from ocular damage despite negative skin tests and continued therapy.

The high preponderance of affected male patients $(71 \%)$ also conforms with the findings of other authors in different parts of the world:- $59 \%$ in Malaysia, ${ }^{16} 61 \%$ in Tanganyika, ${ }^{17} 62 \%$ in Thailand, ${ }^{18}$ $69 \%$ in Australia, ${ }^{19} 71 \%$ in the United States, ${ }^{20}$ and $82 \%$ in Egypt. ${ }^{21}$

Many authors have noted that leprosy affects the anterior part of the eye, with involvement mainly of the cornea and iris. Leprotic disease of the fundus and optic nerve, although described, is very rare. Indeed there was no evidence of any fundus lesions attributable to leprosy in the case examined in this series. Disease of the posterior pole can therefore be eliminated as a significant cause of blindness in leprosy.

Clinically a prominent cause of blindness and visual impairment in this series was the small size of the pupil. Although corneal opacities were present in $68 \%$ of cases, it was noted that they did not necessarily interfere with sight on their own and were not often the main cause of visual disability. Allen and Byers ${ }^{22}$ also found that the corneal manifestations of leprosy were usually not serious for vision unless corneal deposits in the centre were substantial. It was the combination of a small nonreacting pupil with minor degrees of corneal opacification or lens opacities which was responsible in the majority of cases for the visual impairment, and the role of 'chronic iritis' in the causation of blindness in lepromatous leprosy was investigated and forms the subject of a further publication. ${ }^{23}$

The treatment of these late anterior segment complications of lepromatous leprosy was basically surgical. At this stage of the disease local antilepromatous therapy such as sodium glucosuphone (Promin) drops are not beneficial, ${ }^{24}$ and in the absence of active uveitis local steroid therapy has little to recommend it; in addition pupil dilatation could not be obtained by sympathomimetic or parasympatholytic mydriatics. In $34 \%$ of these cases definite posterior synechiae were present and responsible for pupil abnormalities, but nonreacting pupils associated with iris atrophy were equally common, and no synechiae found at operation. Medical therapy by dilating drops or ointments was not therefore found to be beneficial in reducing visual impairment, although local antibiotics were valuable in the prevention of secondary infections. 
The choice of operation lay between optical iridectomy and lens extraction combined with iridectomy. For a long time surgeons have commented on the friability of the iris in chronic lepromatous leprosy making any sort of iris surgery such as a conventional broad iridectomy very difficult, ${ }^{112025-27}$, and iridectomy often failed because of a tendency for the iris to be drawn up and the iridectomy to close. For this reason an inferior sphincterotomy has been recommended to avoid drawing up of the iris into the section. ${ }^{214}$ In many cases in this series it was obvious that there were considerable lens opacities whose extent and distribution could not be accurately determined because of the small nonreacting pupils. The optical iridectomy alone under these circumstances might not prove to be beneficial, and an inferior sphincterotomy would have required a larger corneoscleral section. In addition many patients living far away in remote communities might not have another opportunity to attend for surgery if there proved to be extensive lens opacities.

Lens extraction combined with broad iridectomy and inferior sphincterotomy was therefore undertaken in all patients with small nonreacting pupils whose visual loss could not be explained by corneal opacities alone. The results showed an improvement of the visual acuity of at least 2 lines on the Snellen's chart in $60 \%$, with only $13 \%$ showing no change or worse (Fig. 9). Vitreous loss during surgery was managed by anterior vitrectomy and did not prove in the short-term follow-up period to be a major complication, though obviously these patients will have to be kept under observation. The incidence of postoperative inflammation was very low ( 2 out of 81 cases), and this agrees with the reported safety of cataract surgery in leprosy patients. ${ }^{11115192829}$ Fig. 9 shows that 5 out of 81 cases $(4 \%)$ were worse after surgery, in 3 cases there was increased corneal opacification, in 1 case there were considerable capsule remnants, and the remaining case developed an intractable endophthalmitis - this last patient being the only one who did not receive a 24 -hour course of preoperative antibiotics.

It was evident therefore that in a large proportion of cases blindness occurred through the relatively simple mechanism of the presence of a small nonreacting pupil caused by chronic iris changes combined with corneal or lens opacities.

Although cataract surgery by the method described provides a reasonably safe surgical answer to the late complications of lepromatous leprosy and can improve vision sufficiently to benefit these already severely disabled people, there is an urgent need for energetic research into the cause of these iris changes with a view to possible prophylaxis.
I am grateful to Dr Stanley C. Topple, Dr Mia Topple, Dr Akiko Obara, Dr Yoo Kyeung Un, and all the staff of the Wilson Leprosy Centre and Rehabilitation Hospital, Yosu, South Korea, for their invaluable help and assistance during my 2 visits to their hospital.

I am indebted to LEPRA and St Thomas's Hospital for financial aid, and I thank Mr K. Sehmi for the preparation of the figures and illustrations and Mrs Lesley Gibbons for her secretarial assistance.

\section{References}

1 Kennedy PL. Ocular manifestations in leprosy. Am $J$ Ophthalmol 1952; 35: 1360-4.

2 Holmes WJ. Leprosy of the eye in South Korea. Int $J$ Lepr 1957; 25: 99/103.

3 Pinkerton FJ. Leprosy of the eye, ear, nose and throat. Trans Pac Coast Otoophthalmol Soc 1954; 35: 179-88.

4 Cochrane RG. Leprosy in Korea. Lepr Rev 1956; 27 : 1-19.

5 Cameron AN. Leprosy and its ocular manifestations. Trans Ophthalmol Soc UK 1961; 81: 637-47.

6 Emiru VP. Ocular leprosy in Uganda. $\mathrm{Br} \mathrm{J}$ Ophthalmol 1970; 54: 740-3.

7 Weekeroon L. Ocular leprosy in Ceylon. Br J Ophthalmol 1969; 56: 106-13.

8 Hornblass A. Ocular leprosy in South Vietnam. Am J Ophthalmol 1973; 75: 478-80.

9 Malla OK, Brandt F, Anten JGF. In press.

10 Pinkerton FJ. Leprosy of the eye: an analysis of the record of 512 cases of leprosy in the Hawaiian Islands. Arch Ophthalmol 1927; 56: 42-51.

11 Harley RD. Ocular leprosy in Panama. Am J Ophthalmol 1946; 29 : 295-316.

12 World Atlas of Leprosy. Les amis du Père Damien. Brussels : 1979.

13 Rock R, Obara A, Amundsen AM. Report on an ophthalmological survey of colony patients at Wilson leprosy centre. 1973.

14 ffytche TJ. Cataract surgery in leprosy patients. Proc $R$ Soc Med 1979; 72: 826-30.

15 Choyce DP. The diagnosis and management of ocular leprosy. Br J Ophthalmol 1969; 53: 217-23.

16 Hobbs HE. Leprotic iritis and blindness. Int J Lepr 1972; 40: $366-78$.

17 Mclaren DS, Shaw MJ, Dalley KR. Eye disease in leprosy patients: a study in central Tanganyika. Int $J$ Lepr 1961; 29: 20-8.

18 Wangspa S, Limpaphayom P. Ocular leprosy in Thailand. Trans Asia Pac Acad Ophthalmol 1976; 5: 153-61.

19 Gibson JB. Eye complications of leprosy. Med J Aust $1950 ; \mathbf{i}: 8-14$.

20 Prendergast JJ. Ocular leprosy in the United States. Arch Ophthalmol 1940; 23: 112-37.

21 Wasfy IA, Abdel-Rehim DE. Ocular leprosy in Assiut. Bull Ophthalmol Soc Egypt 1971; 64: 299-327.

22 Allen JH, Byers JL. The pathology of ocular leprosy. I. Cornea. Arch Ophthalmol 1960; 64: 216-20.

23 ffytche TJ. Role of iris changes as a cause of blindness in lepromatous leprosy. Br J Ophthalmol 1981; 65: 231-9.

24 Bouzas A. Long term observation of local application of promine in ocular leprosy. Arch Ophtalmol (Paris) $1971 ; 31$ : 629-34.

25 Wood DJ. Ocular leprosy. Br J Ophthalmol 1925; 9: 1-4.

26 Ebenezer R. Symposium on Uveitis. Proc All-India Ophthalmol Soc 1963; 19: 183-8.

27 Sivasubramaniam P. Some aspects of ocular leprosy in Ceylon. Trans Ophthalmol Soc Ceylon 1971; 10: 13-21.

28 Kirwan EWOG. Ocular leprosy. Proc R Soc Med 1955; 48: $112-8$.

29 Weekeroon L. Ocular leprosy in Ceylon. Br J Ophthalmol 1969; 53: 457-65. 